ANNA PRZYTOMSKA-LA Civita D https://orcid.org/0000-0002-3426-9011

Adam Mickiewicz University in Poznań

\title{
La relación de depredación entre humanos y no-humanos en la ontología de los q'ero de la cordillera de Vilcanota, Perú
}

$\mathrm{D}$ urante mis estudios etnográficos en los Andes peruanos he escuchado repetidas veces a los quechuas decir: - Hay que alimentar a la Madre Tierra, si no, ella se alimentará de nosotros. - La realidad social de los q'ero de la cordillera de Vilcanota está formada no solamente por los humanos (runakuna) sino también por otras personas no-humanas. Los apus (montañas), pachamamas (espacios-tiempos) y machulas (muertos) también forman parte de las comunidades indígenas y correlativamente el bienestar de ambas partes depende de la red de relaciones mutuas (Allen 2002, 2016; de la Cadena 2015; Salas Carreño 2019). La economía y la forma de vida de los andinos están estrechamente relacionadas con las personas no-humanas y reguladas por las normas sociales y prácticas rituales. Según los quechuahablantes todos los elementos del mundo - desde las poderosas montañas hasta las humildes piedras - están animados, aunque pueden variar en su agencia y tipos de las relaciones que establecen. Inge Bolin (1998: 43) escribe que los andinos no separan lo natural de lo espiritual, dado que todos los elementos de la naturaleza viven, sienten, comen y respiran. Sin embargo, según los q'ero estos seres son similares a las personas humanas y se definen por características tales como intencionalidad, voluntad propia, pensamientos, deseos, emociones o personalidad. Por lo tanto, no es de extrañar que no haya palabra "naturaleza" en lengua quechua. A pesar de que las personas no-humanas en los Andes están directamente relacionadas con lo que en la ontología naturalista se conceptualiza como "naturaleza" o "medio ambiente" (montañas, plantas, animales, etc.) o "seres sobrenaturales" (muertos, fantasmas, demonios, etc.). 
Los q'ero son una comunidad quechuahablante que habita la cordillera de Vilcanota en el sureste de Perú. Su territorio está dividido en 5 anexos (comunidades) - Marcachea, Totorani, Hatun Q'ero, Quico y Hapu - que se encuentran en dos provincias del departamento de Cusco: Paucartambo y Quispicanchi. Los miembros de esta etnia se dedican a la agricultura, pastoreo y tejeduría: cultivan papa y maíz, crían alpacas, llamas y ovejas, tejen para uso propio y para la venta. Algunos se dedican al comercio local vendiendo sus productos en los pueblos cercanos. El clima de la cordillera de Vilcanota está determinado por dos estaciones: seca y lluviosa; y tres pisos ecológicos entre 1800 y 5000 m s. n. m. puna (alta montaña), qeshwa (zona intermedia) y junga (ceja de selva). Los q'eros es una comunidad endógama en la cual la familia se estructura sobre una base conyugal de residencia patrilocal cercana y sobre la filiación patrilineal, aunque cabe señalar que en el pasado existió un sistema de filiación ambilineal (Nuñez del Prado Castro 2005: 210-211).

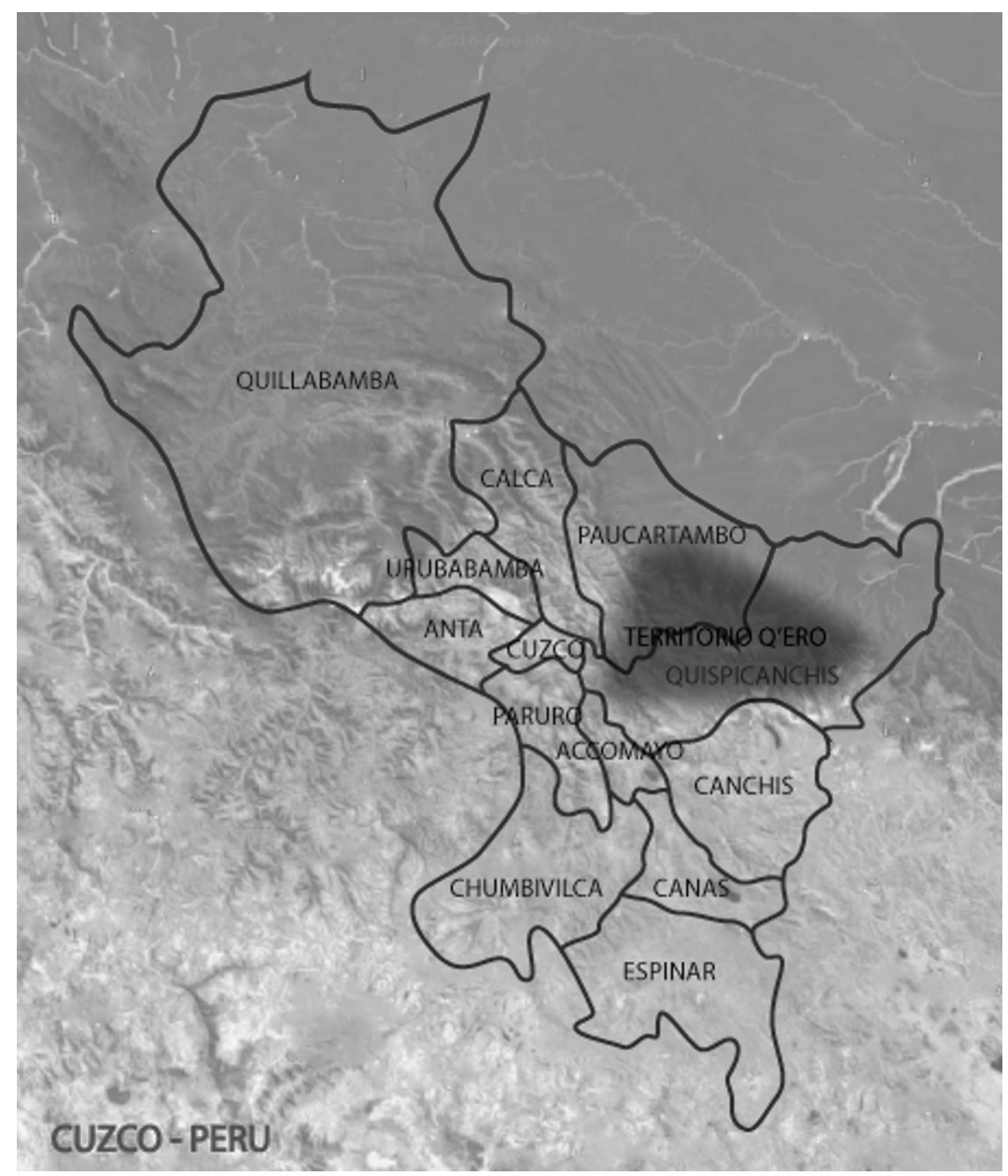

Mapa: Territorio Q'ero (fuente: https://worldconsciouspact.org) 
No mucho tiempo atrás, los q'ero eran un pueblo geográficamente aislado y relativamente poco influenciado por la cultura mestiza. Su aislamiento cultural fue interrumpido en los años 50. Como resultado de la expedición liderada por Oscar Núnez del Prado Castro de la Universidad Nacional de San Antonio Abad del Cusco en 1955. Desde entonces la comunidad q'ero aparece en la conciencia de los habitantes del Cusco y del Perú. Los investigadores miembros de aquella expedición encontraron una comunidad bajo el poder del sistema de haciendas, pero conservadora de una forma de vida poco intacta e influenciada por la época colonial. Prestaron una atención particular a cuestiones como: estructuras de parentesco, tradición oral, cantos, tejeduría o el control vertical de pisos ecológicos. Sin embargo, durante los últimos 25 años, se observa una creciente migración de los q'ero hacia las aglomeraciones urbanas y sus cercanías (Cusco, Ocongate, Paucartambo) lo cual conduce a cambios socioculturales significativos.

La anatomía de relaciones y dependencias entre humanos y no-humanos se manifiesta en diferentes tipos de prácticas cotidianas y rituales: agricultura y pastoreo, movilidad, alimentación, cantos rituales, prácticas chamánicas y medicinales. Esta simple declaración mencionada en el inicio, expresada en el contexto de los rituales agrícolas, oculta dos modelos principales de relación que constituyen el núcleo de la ontología q'ero: intercambio y depredación. Curiosamente, ambos esquemas puden expresarse a través de la locución idiomática "alimentar" (en quechua: mijuy). Esto implica que las relaciones entre seres personales tienen por finalidad alimentarse mutuamente a través de prácticas recíprocas (intercambio) o alimentarse del otro (depredación). En los trabajos anteriores sobre ontología q'ero, hemos analizado el modo de intercambio en el contexto del ritual haywakuy y las prácticas chamánicas (Przytomska 2017, 2019). En el presente ensayo queremos centrarnos en el modo de depredación. Este tipo de relación toma las formas de seducción, relaciones sexuales, canibalismo y secuestro. Las modalidades de depredación que observamos entre los q'ero, las hemos agrupado en tres esquemas que constituyen el eje de nuestra narración y a la vez representan los orígenes o las causas de surgimiento de dichas relaciones. Son: el olvido, la ruptura y la otredad. El análisis se basa en el material etnográfico recolectado durante los trabajos de campo realizados en tres de las cinco comunidades q'ero (Hatun Q'ero, Marcachea, Quico) en los años 2013-2017.

\footnotetext{
${ }^{1}$ La primera etapa de investigación se realizó entre los años 2013 y 2014. Dirijo mi sincero agradecimiento al jefe de Centro de Estudios Andinos de la Universidad de Varsovia, Mariusz Ziółkowski, quien ha hecho posible mi estadía e investigación en el Perú. La segunda parte de la investigación se llevó a cabo entre los años 2015- 2017 como parte del proyecto (2014/15/N/ HS3/01694), financiado por el Centro Nacional de la Ciencia en Cracovia, titulado "Ontología andina desde el enfoque antropológico. El estudio del concepto indígena de las relaciones «humano-naturaleza» en una comunidad quechua de los q'ero, Perú".
} 


\section{Concepto de personas no-humanas y modos de relación en los Andes peruanos}

El objetivo de este artículo es contribuir al debate antropológico sobre las relaciones entre humanos y no-humanas en los Andes. El punto de partida para mi análisis de la ontología q'ero es el proyecto de reflexión teórica llamado "giro ontológico". Este enfoque surgió a través de estudios etnográficos realizados por el antropólogo francés Philippe Descola entre los achuar de la Amazonía peruana y el antropólogo brasileño Eduardo Viveiros de Castro entre los araweté de la Amazonía brasileña. Estos representantes del giro ontológico, inspirados indudablemente por los trabajos de Kay Århem (1990) y Alfred I. Hallowell (1967) 2 enunciaron el animismo y perspectivismo como ontologías amerindias.

Los representantes del abordaje ontológico se enfocan especialmente en la reconceptualización de la oposición naturaleza-cultura y en los estudios de las relaciones entre humanos y no-humanos. El filósofo Graham Harvey (2005: xi) declaró: el mundo está lleno de personas, pero solo algunas de ellas son humanas. Efectivamente, una de las características principales del concepto de personas no-humanas en ontologías no naturalistas es la semejanza con el humano (Descola 2013). El universo y sus habitantes, tanto humanos como no-humanos, están ordenados de acuerdo con un esquema sociocéntrico compuesto por categorías y patrones (modos) de relaciones. Las investigaciones etnográficas entre comunidades no europeas han demostrado que en las ontologías amerindias los no-humanos (animales, plantas, espíritus, muertos, etc.), igual como humanos, son dotadas de agencia, pensamiento lógico y reflexivo, intencionalidad y llevan una vida similar a la humana.

El giro ontológico, que tiene su origen en los estudios amazónicos, se difundió a las investigaciones de los pueblos indígenas en otras partes del mundo y con el tiempo, fue más allá de las culturas originarias. Desde entonces, se han desarrollado muchos trabajos que comenzaron a analizar la agencia de los seres no-humanos en diferentes contextos culturales. Estos últimos años, el abordaje ontológico encontró sus seguidores entre los investigadores de las comunidades andinas: M. de la Cadena (2015), C. Allen (2016), F. Pazzarelli \& V. Lema (2018), J.J. Rivera Andía (2019), M. Sax (2011), G. Salas Carreño (2019). Sus trabajos se concentran en la agencia y subjetividad de los no-humanos (principalmente apus y pachamamas) y las consecuencias políticas en el contexto interétnico e intercultural del Perú. Mi trabajo toma una dirección un poco diferente, enfocándose en

\footnotetext{
${ }^{2}$ En los años sesenta, el antropólogo estadounidense Hallowell (1967) introdujo el término "personas no humanas" (non human persons) para describir este tipo de seres personales que existen en las ontologías no europeas. El antropólogo sueco Kay Århem (1990: 120-121), en el contexto de los makuna colombianos, escribía sobre "cualidades perspectivas" o "el mundo perspectiva", diciendo también que "diferentes clases de seres vivientes son «gente» vestida con distintas «pieles»" lo que, más tarde, Descola utilizó para reformular el concepto del animismo.
} 
el análisis más detallado de diferentes modos de relación que pueden observarse en la cordillera de Vilcanota.

Curiosamente, los representantes del giro ontológico aún no han desarrollado una definición única y común de la ontología, lo que enfatiza la diversidad de encarnaciones de la antropología ontológica (Bertelsen, Bendixsen 2016: 6). Una de las variantes del giro ontológico -con la cual me siento identificada- se define como un experimento metodológico y teórico (Henare et al. 2006; Holbraad, Pedersen 2017). Uno de los postulados del retorno ontológico es tratar al mundo indígena - en su sentido ontológico - seriamente, lo que permite el despliegue de conceptualizaciones indígenas para obviar imposiciones etnocéntricas. El giro ontológico es una respuesta crítica a la antropología posmoderna que se ha desarrollado desde la década de los 80. La perspectiva ontológica, representada por investigadores como T. Ingold, B. Latour, E. Viveiros de Castro, M. Holbraad, M. Pedersen y muchos otros, rompe con la corriente interpretativa en la cual los fenómenos culturales fueron conceptualizados como representaciones, lecturas o interpretaciones. Por lo tanto, es una transición de los estudios de diferentes epistemologías a los estudios de diferentes ontologías. Uno de los objetivos principales de este movimiento teórico es cambiar el aparato conceptual en lo que respecta, entre otras cosas, al cuestionamiento de las nociones que - si bien son apropiadas para las comunidades europeas - se utilizan para el análisis de la ontología no europea (p.ej. cultura-naturaleza, alma-cuerpo, sagrado-profano). Por lo tanto, en lugar de aplicar conceptos analíticos, que provienen de otro contexto cultural, a los datos etnográficos, el antropólogo debería experimentar con los datos etnográficos de manera que éstos cambien el repertorio conceptual de investigador (Holbraad 2012). Esto revela la naturaleza ética y política de este proyecto que nos lleva a distanciarnos de la herencia del intelectualismo neocolonial. La segunda premisa del retorno ontológico es el cambio de paradigma que consiste en la transición desde el estudio de representaciones (culturas) hasta la investigación de ontologías, o diferentes formas de estar en el mundo (Carrithers et al. 2010: 153). Un elemento clave de la antropología ontológica es que el concepto es real y la realidad es conceptual. Esto significa que el mundo que tenía múltiples representaciones culturales ha sido reemplazado por un multiverso (ontologías-mundos). Los representantes de esta variante subrayan que en la perspectiva ontológica la diferencia entre el objeto y su significado ha sido abolida. En otras palabras, la diferencia entre un enfoque epistemológico y un enfoque ontológico es como la diferencia entre "pensar de manera diferente acerca de las cosas" y "tener diferentes cosas para pensar" (Henare et al. 2006). La tercera premisa del retorno ontológico es cambiar el alcance del análisis que consiste en un experimento filosófico-antropológico cuyo objetivo es transgredir nuestra ontología mediante la experimentación con datos etnográficos con el fin de repensar nuestro mundo basándose en las ontologías de los pueblos que el antropólogo está estudiando. Por lo tanto, no se trata sólo de conocer el "punto de vista indígena", sino que se extiende esta tarea a una reflexión antropológica que conduce al descubrimiento de significados ontológicos profundos que pueden 
ampliar nuestro conocimiento del hombre y del mundo. Una de las demandas del giro ontológico es tomar en serio las ontologías no europeas lo que nos permita experimentar más con estos datos para reconstruir las ontologías estudiadas. Por consiguiente, tomarlo en serio significa tratar literalmente lo que dice el otro y no tratarlo como una metáfora o buscar explicaciones "lógicas". Esto obliga ir más allá del mundo del investigador para entender mejor el mundo del Otro.

Con las propuestas del giro ontológico, en este trabajo intentamos reconstruir el mundo de los q'ero, el que co-crean, basado en el seguimiento y análisis de las relaciones que establecen con otros seres que habitan su mundo. Como acabamos de mencionar, el enfoque del giro ontológico requiere tomar en serio los conceptos no-europeos. Por lo tanto, además de investigar el mundo de los humanos, nos sumergimos en la ontología de los no-humanos, dado que la ontología de los q'eros nos obliga a tratar a seres como pachamama, apus u otros como entidades equivalentes que co-crean el mundo social de la cordillera de Vilcanota. Tratarlos como personas reales, más que como representaciones culturales de la naturaleza, sirve para analizar en profundidad esta compleja realidad de relaciones sociales.

En el análisis de relaciones entre humanos y no-humanos en la ontología q'ero, nos inspiramos y dialogamos también con los modos de relación formulados por Philippe Descola $(1992,2013)$. Este antropólogo francés, en sus trabajos, enfatiza que las prácticas y comportamientos observados dentro de una comunidad específica revelan regularidades, continuidades y ciertos grados de automatismo que forman la base de modelos (a menudo) inconscientes de relaciones sociales que unen y estabilizan diversos elementos de la realidad. Descola concluye que, basándose en patrones de prácticas que determinan una amplia gama de relaciones, se puede encontrar la matriz original (modelo) de cada ontología. Descola (2013: 309-335) distingue 6 tipos básicos de relaciones que parecen jugar un papel dominante en diferentes culturas: intercambio, depredación, don, producción, protección y transmisión. Estos modos de relación pueden ser divididos en dos grupos. El primer grupo (intercambio, depredación, don) se caracteriza por relaciones potencialmente reversibles entre entidades similares, correspondientes a esquemas que aseguran el movimiento de algo valioso (alma, sustancia vital, etc.) que circula entre los seres del mismo estatus ontológico. Tratamos aquí con un balance tridimensional: positivo (don), negativo (depredación) o igual (intercambio). El segundo grupo (producción, protección y transmisión) se caracteriza por relaciones unívocas que se basan en los vínculos entre seres ontológicamente desiguales.

Volvamos ahora a la cordillera de Vilcanota para debatir el orden social y ethos cultural de los q'ero que nos permita comprender mejor sus relaciones con los no-humanos. A modo de introducción, nos gustaría mencionar el término allin kawsay que en quechua significa 'buena vida' - es una aspiración realista que se refiere a comportamientos específicos establecidos por un conjunto de patrones culturales. La salud y las enfermedades son percibidas entre los q'ero de manera holística y están estrechamente relacionadas con el concepto de equilibrio del individuo y su entorno (entendido como un universo subjetivo o el espacio-tiempo) 
(por ejemplo: Bacigalupo 1995; Knipper 2006, Salomon 1991: 14) conformado por familia, comunidad, casa, animales de cría, tierras de cultivo, pero también por otros seres que habitan el mismo espacio. $\mathrm{Si}$, según los q'ero, allin kawsay consiste en mantener el equilibrio y el bienestar individual y colectivo, esto significa que los conceptos de salud y de enfermedad en la ontología andina son mucho más amplios que en la ontología naturalista (occidental). Estar sano y tener buena vida se expresa principalmente en los términos de trabajo: "estar listo y dispuesto a trabajar". Según los q'ero, las personas sanas son trabajadoras y ágiles, en cambio las personas enfermas son perezosas, esquivan el trabajo o no pueden hacerlo. Se debe trabajar en paz y paciencia, de lo contrario puede afectar negativamente a los cultivos. Marisol de la Cadena (2015: 285) cita un comentario de Mariano Turpo de Pacchanta (Distrito de Ocongate), un activista indio que dijo que uno de los elementos de una buena vida en los Andes es "un trabajo feliz". Esta actitud es verdaderamente admirable dado que el trabajo de las comunidades andinas está plagado de dificultades y enorme esfuerzo físico. La persona trabajadora acumula propiedades en forma de tierras y animales, lo que muestra su estatus social. Estas dos condiciones - ser trabajador y tener recursos materiales - están interrelacionadas con el sistema de reciprocidad e intercambio llamado ayni, dado que una persona con muchos recursos puede permitirse participar en una amplia red de intercambio. En quechua, una persona rica se conoce como apu y una persona pobre es q'ala (calvo, desnudo). A su vez, una persona que posee bienes materiales, pero no participa en el sistema de ayni, se llama wakcha (huérfano) (Isbell 1974: 111, 138). La vida en la comunidad andina tiene por base la convivencia y la interacción social. Esta dinámica social difiere de los valores occidentales basados en el individualismo y el egoísmo donde las relaciones económicas y el desarrollo se basan en la acumulación de bienes y la competencia. Las comunidades andinas ponen más énfasis en compartir e intercambiar que en acumular. Idealmente, esto significa que las comunidades andinas ahorran y acumulan bienes para asegurar su futuro y compartir el exceso con otros, lo que proporciona el mantenimiento de relaciones armoniosas y solidaridad comunitaria y a la vez forma parte de allin kawsay (buena vida).

Ayni es uno de los principios sociales más importantes en torno a los cuales está organizada la vida de los q'ero. Se reduce a la lógica: dar para recibir y en el quechua significa: retorno, compensación y reciprocidad. En el contexto de comunidad, ayni se manifiesta como el sistema de trabajo recíproco, ayuda comunal y la red de obligaciones sociales. Se revela también en diversos contextos de la vida cotidiana y ritual, como el intercambio de alimentos y otros productos, las funciones políticas, la organización de fiestas colectivas y las prácticas rituales asociadas con las personas no-humanas. Este sistema social de reciprocidad tiene como objetivo garantizar que cada individuo participe en la circulación de bienes y beneficios. Los q'ero tienen 3 tipos de trabajo mutuo, tanto privado como público, simétrico y asimétrico: ayni, mink'a ('faena') y el sistema de cargos. En cualquier caso, la obligación de cada comunero es participar en el sistema de trabajo mutuo. De lo contrario, puede causar una ruptura en las relaciones con 
toda la comunidad, dado que la prosperidad y el orden social dependen de este sistema. ${ }^{3}$ El ayni se revela también en otras actividades diarias informales que son de naturaleza asimétrica, porque no son correspondidas por la misma persona o por igual. De todos modos, lo que fue entregado, tarde o temprano volverá al donante. Incluso, si no ha sido correspondido directamente por el beneficiado, el don será compensado por otro miembro de la comunidad. Esta versión informal del ayni se manifiesta al establecer relaciones de afinidad (matrimonios y compadrazgos) a través de las cuales se distribuye lo que algunos tienen en exceso (tierras de cultivo o animales) o se proporciona el acceso a los pisos ecológicos (puna, qeshwa, yunga). Cabe destacar que, además de la dimensión material del sistema de reciprocidad del que cada individuo y familia se benefician, el ayni es también una forma de generar vínculos, intimidad y humanidad.

Como escribe Enrique Mayer (1974: 38), el ayni es como un cordón umbilical que sirve para alimentar a las personas conectadas a través de él. Como parte de este sistema recíproco, los q'ero mantienen también relaciones con seres personales no-humanos, por ejemplo con los apus (montañas), pachamamas (espacio-tiempo) o machulas (muertos), dado que el bienestar de las comunidades depende -además de trabajo colectivo y ayuda mutua- de las relaciones con no-humanos. La literatura relativa al sistema de reciprocidad (ayni) entre los pueblos andinos y apus o pachamamas es bastante amplia (p.ej. Taussing 1980; Condori, Gow 1982; Bastien 1985; Gose 1986; Allen 1997, 2002; Bolin 1998; Greenway 1998; Sax 2011; Alderman 2015; de la Cadena 2015). Por ejemplo, Catherine Allen (1997: 76) escribe que:

todas las categorías de seres, en todos los niveles, participan en esta circulación cósmica. Las personas mantienen una relación interactiva de reciprocidad, no sólo consigo mismas, sino también con sus animales, sus hogares, sus tierras de cultivo, su tierra y lugares sagrados en el paisaje [traducción propia].

Como último aspecto de la introducción, debemos abordar - al menos brevemente - el concepto de corporalidad. Según los andinos, el cuerpo humano es una especie de sistema hidráulico a través del cual circulan sustancias corporales (Bastien 1985: 7). Los q'ero enumeran seis sustancias básicas que se pueden dividir en visibles: grasa (wira), sangre (yawar); y el semen (wawsa) para los hombres; e invisible: alma (animu) y fuerza vital (samay). Todos los elementos que componen el cuerpo humano - tanto visibles (wira, yawar, wawsa) e invisibles (animu y samay) - no son estables, es decir, pueden ser aumentados, reducidos, perdidos o recuperados. Algunos de estos elementos también están sujetos a intercambio, que es necesario para la reproducción de personas (sangre y semen) o recursos (samay). En este sentido, la persona en ontología andina es inestable y permeable (Przytomska-La Civita 2020). El animu (el doble) es una sustancia individual y personal que determina el carácter y personalidad de la persona, en cambio el samay

\footnotetext{
${ }^{3}$ El incumplimiento de estas obligaciones también lleva a la marginalización del individuo y su eliminación de la lista de comuneros legítimos lo que implica no tomar en cuenta su voz en los asuntos importantes de la aldea.
} 
es una sustancia vital colectiva que circula y tiene que ser intercambiada entre diferentes elementos del mundo. La circulación de esta sustancia es necesaria para la sobrevivencia y equilibrio de todos los seres personales. La circulación de sustancias vitales (samay) entre las personas humanas y no-humanas implica que dichos seres forman una realidad social entendida como una red de constantes relaciones y dependencias mutuas. Los seres no-humanos que tienen el mayor impacto en la vida de los q'ero son los apus y las pachamamas. Las relaciones que se establecen con estos seres tienen un carácter ritualizado. Estos rituales pueden tomar el carácter de ceremonias formales e informales, individuales o colectivas (p.ej. samincha, haywakuy, cantos rituales) y están diseñados para proporcionar rendimientos fértiles, salud para la familia y los animales o éxito en otras áreas de la vida cotidiana. A través de estos rituales los q'ero piden por la salud, la fertilidad para animales, buenas cosechas, etc. $y$, en cambio, alimentan a los apus, pachamamas o machulas a través de los rituales de ofrendas. El ayni entre humanos y no-humanos en los q'ero no es más que el modo de intercambio formulado por Descola. El ayni andino representa una relación simétrica en la que cada transferencia acordada requiere algo a cambio, independientemente de si su valor igual al del artículo recibido y si se trata de un reembolso inmediato o diferido. El saldo de transmisión entre las dos entidades tiene que llevar al equilibrio. Como mencionamos anteriormente, el ayni se expresa a través del acto de alimentación mutua. En consecuencia, el propósito de todas las prácticas es intercambiar sustancias que toman diferentes formas, pero se reducen a un solo factor-samay, la sustancia vital que circula en el mundo. El sistema de ayni es un mecanismo de distribución de esta sustancia - que tiene que estar en movimiento continuo - de una manera sostenible. Esto nos conduce a la conclusión de que en la ontología andina la vida es un flujo continuo de sustancias.

Ayni es una estrategia ontológica con la cual el mundo y todos sus componentes siguen reproduciéndose. Pero ¿qué sucede cuando se rompe esta regla y se detiene el flujo constante de la sustancia? Según los q'ero, romper dicha relación de intercambio, a consecuencia del abandono de ayni, puede asociarse con una reacción negativa o depredadora de los no-humanos, lo que hemos observado en varios contextos y versiones. En este lugar nos referiremos nuevamente a Descola (2013: 309-335) según quien el modo de depredación (que puede llamarse robo o apropiación) es una asimetría negativa - opuesta al don - donde el sujeto $X$ (depredador) toma algo valioso (puede ser su vida, su cuerpo o energía vital) del sujeto Y (víctima) sin ofrecer nada a cambio. Sin embargo, esto no se debe al deseo de herir o dañar a alguien, sino al imperativo interno y a las limitaciones del sistema. Éste es un ejemplo de destrucción productiva, necesaria para la supervivencia de un individuo y no tiene relación con la crueldad desinteresada o con un deseo perverso de matar al otro, sino, todo el contrario, transforma a la víctima en el objeto de mayor importancia. En el contexto amazónico, la depredación, estrictamente conectada con el parentesco y consanguinidad, es ante todo una estrategia para integrar la otredad, tanto humana como no-humana, para adoptar o convertir a esos seres en parientes: el sujeto debe tomar posesión de 
otro ser y asimilarlo en sí mismo a través de guerras, secuestros de mujeres, canibalismo real o simbólico. Mientras que en las culturas amazónicas este modelo de relaciones ha sido ampliamente discutido y presentado en muchos ejemplos etnográficos (por ejemplo: Vilaça 1992; Viveiros de Castro 1993, 1996; Descola 1996; Fausto 2007), en el caso de las culturas andinas es un tema prácticamente ausente. Veremos que, en el contexto andino, la depredación se refiere a la absorción de una sustancia vital la que se manifiesta a través de la estrategia de alimentarse del Otro, aunque no constituye un modo ontológico primordial, sino un modo sustitutivo que se revela cuando el sistema de intercambio fuera infringido.

\section{Aquellos que han entrado en el olvido}

Para los q'ero las relaciones con los apus y pachamamas son de mucha importancia, dado que están estrictamente relacionados con la agricultura y el pastoreo. En la ontología q'ero los apus son dueños de los animales (salvajes y domésticos) y minerales y, a su vez, las pachamamas son las dueñas de cultivos. La figura del "dueño" es conocida en todo el continente americano y en el contexto amazónico personifica una especie de hipóstasis de especies animales (por ejemplo: Bonilla, Lima 1995; Viveiros de Castro 1998; Tola 2012, 2016). En cambio, en el contexto andino, los animales y los cultivos constituyen los recursos de los no-humanos que en mismo tiempo son objeto de intercambio con los humanos lo que es crucial para el bienestar de las comunidades andinas. Cuando la gente olvida de sus deberes rituales -como resultado de la aculturación, la conversión religiosa, el descuido $\mathrm{u}$ otras razones- se hace expuesta a las reacciones negativas de los no-humanos y consecuencias dramáticas: desde choques de rayos, la infertilidad de animales, las malas cosechas o enfermedades y muerte. Gabriel Martínez (1983: 87) señala dos caras de los apus, alegando que pueden ser amistosos $u$ hostiles al hombre, pero que su comportamiento depende de la actitud inicial del hombre. Es necesario añadir que en este caso el humano representa el disparador que infringe el orden de las cosas y de esta manera desencadena el mecanismo depredador. Por ejemplo, la persona que mata a un animal salvaje sin permiso del apu al que ése pertenece, está expuesta a su ira y su castigo:

- En Qompipampa, allí había un animal salvaje; era de allí. Así un comunero dijo: - ¡Captúrenlo, agárrenlo! - y fueron [a] degollar ese animal salvaje. Fue Casimiro Espinosa, ese que ha dado orden. (...) Habían traído la vaca salvaje. Entonces, no era propiedad de ellos. Era ganado de Qompipampa. Era un encanto ese animal. En Qompipampa estaba lleno de animales encantados. (...) Degollaron la vaca, y después se llaman entre los apus. En la noche los apus se comunican. Entonces la gente duerme en la cueva, cueva de piedra. Dicen que así cuando estaban durmiendo antes de preparar la cena y cuando estaban durmiendo, se estaban comunicando los apus, de mayor a menor; así diciendo: - Ese ganado que se llamaba Runtupuku ['cáscara de huevo'], ¿quién ha degollado, quién se le 
ha llevado Runtupuku? - Otro dice: - ¿Cuál de nuestro ganado no hay? Habían degollado el ganado blanco como cáscara de huevo. (...) ¿Quién lo ha llevado, adónde? - Los apus dicen: - Hay que buscarlo. Ahora mismo vamos a buscarlo. Inmediatamente, al que habían agarrado era el presidente [kamachikuq]. Al mismo rato el apu lo ha comido. (...) el presidente murió en la cueva. Se lo ha comido el apu Qompipampa, el dueño de la vaca.

La historia contada por Agosto de Marcachea describe la trágica consecuencia de romper el orden establecido entre humanos y no-humanos: la apropiación indebida por parte de los humanos de una vaca perteneciente al apu Qompipampa. Ocurren eventos similares cuando los seres humanos matan animales salvajes, p.ej. pumas, vicuñas o tarucas. Cabe destacar que en realidad la venganza de los no-humanos es una reacción al comportamiento humano que revela una actitud depredadora (no recíproca).

Los apus son también dueños de minerales preciosos. El oro fluye a través de las venas de la tierra y es como la sangre para los runakuna. Por esta razón nadie puede levantar el oro sin permiso. Los comuneros de Quico cuentan la historia de Mallki que tuvo lugar en los años noventa. Mallki - un hombre de la ciudad, muy ambicioso y rico - oyó hablar de una leyenda sobre el oro ubicado en las cercan del apu Osanaku, en las tierras q'ero. Mallki - muy bien preparado y abastecido partió a la montaña. Sin embargo, durante su aventura sucedió algo inesperado. Los q'ero relatan que al acercarse a un lugar llamado Qollpayoq (lugar de oro), Mallki desapareció y nunca ha regresado. Nadie sabía lo que le había pasado. Según los comuneros, cuando alguien se acerca a Qollpayoq, de repente estalla una tormenta. Los depósitos de oro están protegidos por las serpientes venenosas (probablemente Tachymenis peruviana) - los guardianes del oro. ${ }^{4}$ Otro comunero de Quico contó una historia parecida acerca de un helicóptero que había caído cerca del apu Mama Juana:

- Dicen que en ese helicóptero traían harto oro, más o menos $80 \mathrm{~kg}$. De Puerto Maldonado lo traían. (...) Y neblina, mucho tapa y montaña es grande, alta. Y se chocan acá. Y ese accidente fue causado por los apus. No quería que lleven ese oro. Cuando alguien quiere robar su oro, eso hacen, mucha lluvia, neblina, mucho viento. (...) 5 o 6 personas murieron. Y después no encontraron nada, ni una chispa de oro. Los apus lo ocultan. El oro es como sangre para los apus. (...) Es malo buscar oro, es muy encantado, pertenece a la tierra. Uno no puede levantar el oro gratis, tienes que dar un despacho o sacrificar un animal. Si no podemos morir, ellos son muy enamorados de los oros. Es difícil para recogerlo.

\footnotetext{
${ }^{4}$ Los q'ero explican que, los senderos incas corrían a través de sus tierras, conectando las montañas con la selva, desde donde se extraía el oro y se lo transportaba hasta Cusco. Cuando una llama o mula sucumbían a lo largo del camino, los arrieros escondían el oro cerca del sendero y, según la leyenda, algunos de estos tesoros siguen ocultados en las tierras q'ero hasta hoy día.
} 
Los andinos llaman a los apus "los que organizan" (kamachiq - 'el que organiza') la vida social y la naturaleza (Ricard Lanata 2007: 54). Sin embargo, los acontecimientos descritos anteriormente muestran que la agresión de los seres no-humanos constituye un mecanismo de recompensa. La pérdida de un recurso en particular (animal, oro) se compensa en forma de vida humana, razón por la cual los q'ero dicen: "el apu se lo comió".

La cara depredadora de los apus o pachamamas se revela también cuando las personas, como resultado del olvido u omisión, rompen los lazos de reciprocidad establecidos anteriormente. Los no-humanos que forman parte de la pacha (comunidad local), quienes no fueron alimentados, se convierten en el peligro para la comunidad. Este fue el caso del apu Ankashchaki que se convirtió en un ser depredador, puesto que los aldeanos dejaron de realizar los rituales de ofrenda (haywakuy). El cerro hambriento secuestraba o, como dicen los q'ero, comía los animales y niños:

El apu se abre y rapta a una criatura o mujer. Comentan que dentro de apus hay ciudades; allí se lo llevan a los niños y otros. Como que tuviera una puerta con su llave; y se cierra, de una vez lo cierra. Paqos comentaban que allí [al pie de Ankashchaki] hay una piedra gigante antigua, sobre esa piedra la wawa [niño] bailaba; y después de repente desaparece... Ankashchaki era muy bravo.

Los q'ero relatan que Ankashchaki, en forma de un hombre mayor y blanco, engañaba y secuestraba a los niños a quienes ofrecía dulces. Apenas los niños se acercaban a él o a la piedra en la que dejaba los regalos, desaparecían sin dejar rastro. Según los relatos, adentro de las montañas, conectadas con el mundo humano a través de entradas ocultas (punku), hay ciudades con ricos recursos (productos, tiendas, animales). La historia subraya que en el pasado el apu Ankashchaki fue descuidado por los comuneros, por lo que se convirtió en un depredador. Después de la intervención del altomesayoq (chamán), quien llevó a cabo una serie de rituales de ofrendas (haywakuy), el cerro dejó de amenazar a la gente, lo cual nos indica que la relación depredadora es reversible. Esto significa que en este sistema ontológico la relación de intercambio y depredación puede estar sujeta a un proceso de reversión o reposición, dado que en ciertas circunstancias pueden reemplazarse entre sí.

Las pachamamas ('tierras'), como los apus, también tienen su rostro depredador. He oído muchas veces entre los q'ero que "la pachamama se alimenta de la gente", lo que demuestra que la depredación de pachamamas también se manifiesta en términos de alimentación (mijuy). Generalmente, esto sucede en dos contextos diferentes: (1) cuando las personas han dejado de hacer ofrendas rituales (intercambio) o (2) cuando atraviesan las tierras hambrientas - desconocidas y alejadas - que no tienen establecidos los vínculos de reciprocidad con ninguna comunidad. Según los q'ero el hecho de alimentarse del cuerpo humano puede tener una dimensión física (secuestro; absorbiendo al hombre bajo la tierra) o "espiritual" - el robo de su animu. En el primer caso, una persona es literalmente arrastrada al interior de la 
pachamama. Según María Apaza, que vivió varios meses en $u k h u$ pacha ('el mundo de abajo'), hay dentro de la tierra ciudades donde viven personas de baja estatura (enanos). El segundo caso - el secuestro del sustrato "espiritual" - provoca una enfermedad llamada hallpa hap'isqa, causada por el robo del animu. Para curar hallpa hap'isqa es necesario realizar una ofrenda ritual (haywakuy) que consiste en "alimentar" al ser no-humano y persuadirlo para que devuelva el animu de su víctima.

Como podemos observar, el patrón del proceso de reversión se repite nuevamente. En el contexto de la pachamama, como tierra animada, la descripción etnográfica presentada anteriormente nos invita a reflexionar acerca del concepto de movilidad en la ontología q'ero. Como mencionamos, las tierras olvidadas - las que no mantienen lazos de intercambio con los humanos - son depredadoras. Esto nos hace entender que la movilidad en el contexto andino se asocia con los conceptos de Otredad y depredación, dado que el acto de desplazarse significa: abandonar el espacio de familiaridad marcado por las relaciones de intercambio y entrar al espacio desconocido cargado potencialmente de depredación u Otredad. En otras palabras, el acto de desplazarse requiere exponerse a los encuentros con seres desconocidos que no pertenecen a la misma pacha ni al mismo sistema de intercambio de recursos y sustancias. Por lo tanto, la falta de relaciones de reciprocidad significa la depredación potencial. Por esta razón, los q'ero realizan el ritual de phukuy (soplo ritual) que permite a los viajeros comunicarse con los seres desconocidos a quienes encuentren en su camino. El objetivo de este ritual, que consiste en enviar el samay mediante hojas de coca ( $k^{\prime}$ intu), es saludar a los apus y pachamamas, pedirles permiso y alimentarlos con energía vital. Es una manera de domar la Otredad y transformar la depredación en intercambio.

Otro ejemplo que representa el esquema de olvido son las sirenas andinas que viven en el mundo subacuático (ríos, lagos, lagunas o cascadas). Según los q'ero son dueños de agua y peces, pero también se destacan por sus habilidades musicales. En tiempos antiguos los q'ero mantenían las relaciones de intercambio con estos seres acuáticos, realizando rituales de reciprocidad y cantando sirina tak'i ('canción de sirena'). Por su parte, los chamanes realizaban el ritual llamado sirinakuy ('convertirse en sirena'), entrando en el mundo subacuático y casándose con sirenas con el propósito de aumentar sus poderes mágicos. Ricard Lanata (2007: 397) describe el ritual de sirinakuy realizado por Leonardo Chullo:

Sobre las orillas del lago Laramani, yo recojo gran cantidad de flores (...). Echo flores al lago, las siembro a todos los vientos en el lago, y en acto seguido, me desvisto completamente, (...) y entro resueltamente al lago, y entonces me baño. Ahí me hago sirina, para ser más poderoso, y [las sirina] me bautizan (...). En este lago, me veo como en un espejo, veo un reflejo que se parece a mi rostro, como si se tratase de otra persona, que hablaría en mi lugar, así es como me siento, (...) me siento totalmente transformado. (...) Pero si tú quieres acercarte a este lago, si tú quieres llegar a la orilla, tienes que ofrecer un despacho, ahí, en el borde del agua, tienes que hacer libaciones, rociar los alrededores, de esta manera yo 
entro en este lago. $\mathrm{Y}$ en el momento de salir del lago, me pongo ropa nueva (...). Solamente después de haber entrado al lago, y justamente por eso, es que yo obtengo mis poderes...

Según los q'ero, en los viejos tiempos, los chamanes podían llamar a las sirenas tocando música, utilizándola como una forma de comunicación. Tocando la flauta y cantando sirina tak'i, los chamanes sacaban provecho de los seres acuáticos que los llevaban al mundo subacuático y les ofrecían sus tesoros. Por otro lado, la música es el dominio de sirenas. Los q'ero comparten el concepto de que las sirenas son músicos perfectos que cantan y tocan la guitarra, el charango y la flauta y de esta manera hechizan a sus víctimas. Asimismo, cuando los andinos dejan los instrumentos musicales en la orilla del río por la noche, las sirenas se convierten en personas, tocan estos instrumentos y los sintonizan.

Esta capacidad de transformar los tonos que ofrece la naturaleza, y producir las variaciones que deleitarán a los seres humanos puede ser otorgada por la sirena. La recibirán los instrumentos que, tras un ritual riguroso, se depositan por la noche al borde de un puquio o manantial, donde se sabe que concurren o habitan las sirenas. La quena, el pincullo o las "tijeras" de los danzantes entre otros instrumentos, se dejan "dormir" en la orilla, evitando la curiosidad de observar a quienes les proporcionan la virtud de ser sonoros y fortalecer la destreza de los músicos. Si se siguen las reglas mencionadas, el favor de las deidades solo tendrá consecuencias benéficas (Tomoeda 2005: 158-159).

El autor habla de un "ritual riguroso" que no es más que una ofrenda (haywakuy) mediante la cual se alimenta a las sirenas con productos agrícolas y hojas de coca por su trabajo de afinación. Otras historias andinas muestran el papel de las sirenas como cuidadoras de los depósitos de agua donde ofrecen peces a la gente o multiplican sus animales a cambio de regalos (Gutiérrez 2012: 24-26).

Los testimonios mencionados revelan la naturaleza positiva de las sirenas, mostrándolas como dueñas de los peces, aguas y habilidades musicales. Sin embargo, en la cordillera de Vilcanota estos seres acuáticos tienen muy mala fama, dado que, como resultado del abandonado ritual y olvido de las canciones, las sirenas - hasta ahora amistosas - se han convertido en seres peligrosos para el hombre. Los q'ero cuentan que estos seres acuáticos suelen transformarse en personas - amante, expareja o un guapo desconocido - y seducir a su víctima para tener relaciones sexuales con él(ella). La mayoría de las veces, por la mañana, la sirena desaparece, sin dejar rastro:

Dicen que aparecen como chicas hermosas u hombres guapos y cantan maravilloso. Echan encantos, cantan cuando sale el sol o por las noches. Dicen que antes, durante el puqllay ('carnaval'), los sirinas venían y bailaban. (...) Salían de las cascadas y bailaban por la noche y (...) cantaban un tipo de canción, pero diferente, así, hechizaban y se llevaban a chicos y chicas. Y cuando pasaban la 
noche se embarazaban. (...) A los hombres un tumor aparece en las piernas y sale como si fuera un gusano. Félix Machaca de Marcachea un día estaba en su chacra. Y se le acercó una mujer. Desde entonces ha caído enfermo y ha muerto después de 8 meses.

Los q'ero narran que las sirenas que fueron olvidadas buscan compañía. Por esta razón seducen a los humanos con su belleza, canto hermoso y ofreciéndoles tesoros del mundo submarino. En la comunidad de Marcachea, escuché el testimonio de José quien una vez vio una tienda a la vera del río. Allí encontró a una hermosa joven cantando. El joven se acercó a la chica, preguntándole qué estaba haciendo allí y de dónde venía la tienda que nunca antes había existido. La desconocida le dio algunos dulces y lo invitó a la tienda alegando que tenía muchas otras cosas que ofrecerle. Sin embargo, José supuso que la chica fuera en realidad una sirena. Se apresuró a su casa y cuando regresó al día siguiente, la tienda y la joven habían desaparecido. Un hombre que cae en el encanto de la sirena y va a su mundo subacuático permanecerá allí para siempre. Estas narraciones representan, igual como sucede en caso de las pachamamas o los apus - los motivos de secuestro.

La historia que sigue, nos presenta otro motivo - la seducción y las relaciones sexuales entre humanos y no-humanos que podemos encontrar en diferentes ontologías amerindias. En noviembre de 2010, en Marcachea tuvieron lugar acontecimientos muy trágicos. Marcela, hermana del jefe de la comunidad (Mario), era una mujer casada y con dos hijos. Una vez, conoció a un apuesto joven con quien pasó la noche mientras su esposo estaba ausente. La mujer se enfermó, poco a poco iba perdiendo fuerzas y su barriga comenzó a crecer, lo que sugería que había quedado embarazada. Unos meses más tarde, la mujer dio a luz. En el parto participaron dos hombres: Mario (su hermano) y Florentino (chaman y obstetra). Mario dijo que de la barriga de la mujer salió un ser deformado que se parecía a un pez en lugar de un niño. Florentino dijo que la mujer había parido una masa de carne: mitad humana, mitad pez. Los hombres mataron a ese no-humano, lo arrojaron al fuego, enterrando sus restos lejos de la comunidad para evitar el peligro. La mujer murió después del parto. Según los testigos, Marcela confesó haber tenido relaciones sexuales con un extraño que en realidad no era un humano sino un ser depredador. Después de tener relaciones sexuales con una sirena, la gente cae enferma y luego muere. Las mujeres creen que están embarazadas, dado que su vientre va agrandando. Sin embargo, no se trata de un embarazo, sino de un "ser parasitario" llamado saqra que se alimenta del cuerpo humano. En cambio, los hombres presentan otros síntomas: un quiste o un tumor. Otro caso ocurrió en Hatun Q'ero. Una vez, un hombre pasó la noche con una sirena pensando que era una mujer. El resultado de ese romance fue una enfermedad que se manifestó por la pérdida de peso y terminó con la muerte del hombre. Esta enfermedad letal se llama "secada": - La sirina te come, por eso te flaqueas - dice uno de los comuneros y agrega que las sirenas son invisibles, se sientan en la nuca de la persona, "amarran su boca y por eso no puede hablar" y se alimentan de sustancias corporales de su víctima. 
Las sirenas actúan de manera parecida que los apus y las pachamamas. En consecuencia de seducción y relaciones sexuales, se alimentan de los humanos de forma parasitaria (visible o invisible). En otros casos, las sirenas secuestran y atrapan a las personas en el mundo subacuático, lo que significa la desaparición física de la persona. Cabe destacar que en las ontologías amerindias la sexualidad, en el contexto de relaciones con no-humanos, es generalmente considerada como una forma de establecer los lazos, en este caso de depredación (en otros casos puede servir también para establecer la relación de intercambio).

Considerando el esquema de olvido en el contexto de relaciones con pachamamas, apus y sirenas andinas, cabe destacar que estos seres forman un grupo de personas con las cuales los humanos establecen y mantienen las relaciones de intercambio. Esos seres desempeñan un papel muy importante en el sistema de un flujo continuo de sustancias, dado que son dueños de los recursos importantes para los runakuna (animales, cultivos, agua, minerales). En el momento de la ruptura del imperativo de reciprocidad, la relación existente se transforma en un modo de depredación revelando las características del sistema ontológico: el flujo de sustancias tiene que continuar. Cabe señalar que, aunque la depredación no es el esquema ontológico principal, existe como un modo sustitutivo, dado que reemplaza la relación de intercambio en el momento en que ha sido perturbada. Además, el modo de depredación nos revela una información importante: los no-humanos no son autosuficientes, necesitan otros seres para sobrevivir, al igual que los runakuna.

\section{Aquellos que han fallecido, pero viven entre los vivos}

El kukuchi representa el esquema de ruptura del orden social y depredación interna, dado que se trata de un humano que se transforma en agresor. Según los q'ero, kukuchi es un difunto condenado cuyo proceso de muerte no ha llegado a su fin. Esta anomalía es causada por la ruptura del tabú cultural: el incesto. Los q'ero dicen que después de la muerte, el alma de la persona que cometió el incesto - en vez de dirigirse al interior de los apus (montañas) - regresa al mundo de los vivos donde recupera su cuerpo. Convertido en kukuchi, comienza su vagabundeo por las montañas, en una suspensión ontológica: no es ni humano ni difunto. Los q'ero comentan que, después de la muerte, kukuchi sale de la tumba en busca de alimento que es la carne humana. En Hatun Q'ero escuché la siguiente historia:

- Estaba haciendo chacra en Hatun Q'ero. Todos, ¿no? Más o menos eran 3 de la tarde. Y había una mujer embarazada que bajaba desde una montaña con sus llamas. Y había ahí una pequeña quebrada y ella estaba mirando cómo estamos sembrando la papa. Y entra la mujer a la quebrada y una llama suri entra por detrás y cuando entra a la quebrada no salía, no salía. Nada. Y cuando no salió ya como una hora, y ya era hora de descanso y, decimos, este, ya llegó su día, como estaba embarazada. Y se fueron dos personas para que miren. $Y$ dicen que cuando 
llegaron el kukuchi ya se había comido a la mujer. Dicen que estaba comiendo al bebe. Esa alpaca que entró por detrás de la mujer era kukuchi. (...) Entró como alpaca, pero ellos vieron el kukuchi comiendo al bebe. Vieron un hombre vestido con la ropa de difunto.

Como nos indica este testimonio, el estado oncológico de kukuchi puede ser modificado. El condenado puede transformarse en animales para ocultar su identidad o para recorrer largas distancias. Esta historia muestra que los comuneros no observan directamente el proceso de transformación, sin embargo, al ver - en lugar de una alpaca - a un hombre que consume la carne humana, sacan la conclusión de que el animal era en realidad un kukuchi. Esta historia indica también que el condenado puede ser reconocido por la vestimenta del difunto. Los q'ero afirman que al kukuchi se lo puede reconocer también por la ropa manchada o por la piel en la etapa inicial de descomposición. Señalan también que el condenado arrastra cadenas detrás suyo o puede tener la forma de un esqueleto. Por lo tanto, a kukuchi no le gusta mostrar su rostro, temiendo ser reconocido. A menudo usa un sombrero, una capucha o camina con la cabeza agachada. El lugar que habita kukuchi indica su exclusión y estado no-humano. El condenado deambula por la montaña alta donde sufre de frío, hambre y molestias. Vive en lugares alejados, salvajes y despoblados. Otro elemento que indica el estado no-humano y depredador de los kukuchi es su alimentación de la carne humana. Cuando a veces son tratados con comida humana, se niegan y dicen que no tienen hambre, lo que termina siendo un comportamiento inusual. Este es un elemento muy importante, porque la comida constituye a menudo un determinante de identidad, estado económico o género (López García 2001), pero en este caso también del estado ontológico - no-humano.

Esta otra historia sobre los sucesos en Hatun Q'ero también se refiere a la transformación del condenado en animales y a las acciones emprendidas para neutralizarlo:

- Había un caso en Hatun Q'ero... se murió un hombre y cuando llevaban su cadáver al cementerio se paró. Y toda la gente se asustó, luego volvió a morir. (...) después de haber muerto volvió a salir de la tumba. Una vez se acercó a una persona... (...) a un viejito y le dijo: - Yo estaba con mi hermana por eso no puedo morir, el apu no me recibe, si yo bebería el agua helada de Wamanlipa volvería a vivir. Pero me quemaron los ojos y solo no puedo ir. (...). - Luego apareció en Marcachea (...) Entonces la gente se enteró de esto y se fue a ver su tumba y vieron que una parte de la tumba se había hundido y que no había cuerpo. Otro día alguien vio que una mariposita entraba y salía. Esta vez encontraron cuerpo, y vieron que se volteó, pero estaba intacto. Luego le cortaron la cabeza. La sangre corrió como de vivo. Tenían que enterrar la cabeza en otra montaña y el cuerpo enterraron en el mismo lugar. Para que no se junte más. 
Los q'ero cortan la cabeza al difunto, de donde fluye la sangre como si éste viviese. Este detalle indica que, en realidad, esas personas no están tratando con el cuerpo de un fallecido, sino con el de un kukuchi cuyo proceso de muerte no ha terminado. Prestemos atención a un pequeño detalle de la historia anterior, en la cual los eventos anormales ocurren durante el entierro del difunto. Este hecho nos hace entender que la transformación del difunto en kukuchi sucede muy rápido, dado que los síntomas de transformación en condenado estaban visibles durante el funeral. Por esta razón, los andinos vigilan a los muertos toda la noche. Por un lado, el velorio es una manera de despedirse del difunto, pero a la vez una forma de evitar el peligro. Los q'ero hablan de dos formas de matar al kukuchi: hay que quemarlo o cortarle la cabeza, que luego debería ser enterrada en otro lugar para no poder regresar al cuerpo y volver a la vida. Otra historia que tuvo lugar en Quico Chico nos cuenta sobre una mujer que se convirtió en kukuchi en consecuencia de una brujería y del incesto. La historia ilustra las razones de su transformación, las reacciones de los aldeanos y la forma en que la mujer fue asesinada:

- Persona muere, la enterramos y después de 2-3 meses sale. Kukuchi es, sale con su cuerpo y está caminando por las montañas. Y la gente normal lo ve, como está entrando [a la tumba] o está haciendo su tejido o está peinando su cabello. Yo vi uno de Quico Chico, Berta Champi. Salió de su sepultura, era condenada. (...) Cuando entra hay que cortar y quemar la cabeza. Para que no salga, ¿no? A veces hacen sexo con su yerno, o hijo, o madre, padre. (...) Sexo con hijo es más grande pecado que matar a alguien... Después de 3 meses cortamos la cabeza de esa mujer que ha hecho sexo con su yerno. La cortamos con una hacha y sangre así, chuuuuu. Vivo, era vivo. (...) Después quería comer a los niños ya. Apareció diciendo: sálvame, hice esto, tuve sexo con mi yerno. Era vecina de Benito. Son brujos ellos. Entonces su cabeza llevaron a la montaña Pumachunta (...) para quemar... pero se les escapó la cabeza, fuuuu, la energía la jala para su cuerpo hasta mitad de camino. Después: - Carajo, esa puta se me ha escapado, ¡carajo! - El viento fuerte, neblina ha bajado... La energía es muy fuerte. Recién la agarran entre 5 o 6 personas abajo. Y de vuelta arriba, solo la enterraron, no quería quemarse, no agarraba ni gasolina ni alcohol, nada. Ni pelo, ni piel se quemó. Los ojos eran normales, como de vivo. Toda la comunidad hicimos despachos [haywakuy], y no volvió, como la enterramos en dos partes diferentes.

Esta citación describe eventos extraordinarios: los comuneros cortan la cabeza de la cual fluye la sangre viva; la cabeza cortada cobra vida y se escapa; a pesar de verter alcohol sobre su cuerpo, no quiere prender fuego. Los q'ero queman o descuartizan el cuerpo de kukuchi para que quede inofensivo. Todos estos eventos extraordinarios fueron causados por el hecho de que Berta era una bruja. Más adelante en la historia se explica la relación entre el incesto y los actos de brujería que a veces se realizan para enriquecerse. 
- A veces pasa por los animales.... Cuando quieres animales muchos y rápido... ellos hacen sexo entre familiares. Entonces eso hizo Berta. Pero nadie puede saber eso. Ni su hija, ni su marido. Y vienen animales, ufff, rápido. Y no es una vez, cada vez tienen que hacer esto. Es energía negativa, brujería es pues. Ese animal no es para tu vida, no es para tu bien, después tú mueres y todos animales después de 5-6 meses mueren también. Eso no es verdadero, es encantado. En 2 años aparecen 100 alpacas, 100 lamas, 100 ovejas. Así, normal, imposible. ¿De dónde vienen? Entonces la gente sabe, siempre hay chismes. O pelean y avisan. Nunca hay tranquilidad, puede ser 1 año de tranquilidad y cuando saben tú animal ya cae ya, enferman y se mueren. También hacen eso por la plata, o por trabajo. Pero es por momento. Después se cae, dinero, fertilidad, chacras, todo. Después siempre ya cayendo, ya problemas entran poco a poco.

Este fragmento explica que, en el caso de Berta de Quico, el acto de incesto fue utilizado para actividades mágicas - la multiplicación o reproducción de los animales. La ruptura de los tabúes está conectada aquí con prácticas mágicas que rompen el orden del mundo andino. La reproducción animal no es el resultado de la reciprocidad, sino el efecto de acciones mágicas. Estas anormalidades conducen a otra transgresión anormal en la que desaparece el límite entre la muerte y la vida (Fourtané 2015: 162). Después de la muerte, la persona que rompió un tabú debe sufrir las consecuencias y queda también excluida del orden social humano después de su muerte lo que atestigua la fuerza de ese tabú en la cultura andina.

Aquí podemos hacernos una pregunta: ¿el acto de comer la carne humana significa canibalismo? El incesto en el contexto de la brujería realizada con un objetivo económico significa la ruptura o el rechazo del intercambio. Si los miembros de una familia aumentan sus rebaños a través de las prácticas de incesto, eso significa que perturban el orden social: no solamente el tabú cultural (relaciones sexuales con los familiares), sino también un sistema establecido que involucra el intercambio entre diferentes grupos de seres (humanos y no-humanos). Suponiendo: si los rituales que hacen aumentar los rebaños de animales debilitan de alguna manera los recursos del resto de la comunidad, o incluso de la pacha, esto puede significar que esa persona, aún antes de morir, es un depredador que se alimenta del cuerpo colectivo de la comunidad. Esto explicaría por qué esta persona después de la muerte se convierte en un ser no humano que se alimenta de la carne humana (depredador interno - caníbal). Ricard Lanata (2007: 126), para explicar el fenómeno de kukuchi en el contexto de incesto (relaciones con familiares que perturban el intercambio), utiliza el concepto de canibalismo simbólico definido por Lévi-Strauss en otro contexto cultural (sociedades exógamas). Miremos esto en detalle. Para empezar, en el caso de los q'ero se trata de las relaciones de incesto esporádicas, usadas para la brujería, y no de relaciones permanentes que podrían perturbar el intercambio de mujeres. Luego, hay que subrayar que el kukuchi no puede ser visto como un caníbal, porque según los q'ero el condenado ya no pertenece a la colectividad humana. A mi entender, la citación siguiente disipa por completo las dudas acerca de la cuestión de canibalismo. Esta actitud 
radical hacia el kukuchi y el acto de incesto nos revela un punto de vista muy importante sobre el concepto de persona y el concepto de deshumanización:

(...) se emborrachan mucho y violan [a] sus hijas o nietas, hasta con su madre. Y es gran pecado, por eso cuando la gente se entera, le agarran y le matan, le queman. Ellos igual se vuelven kukuchis. Entonces hay que otra vez matar a este kukuchi. Ellos ya saben que será $k u k u c h i$ entonces lo matan no más.

Los q'ero señalan que el que fue atrapado en un incesto, es sentenciado a muerte: Cuando la gente se entera, lo atrapan y lo matan. - Esto se debe a que, a los ojos de los q'ero, esta persona (aunque viva) ya no es completamente humana, se ha convertido en vida en un depredador y después de su muerte se convertirá en un kukuchi. Los actos de incesto y brujería dan testimonio de la deshumanización y depredación, tan peligrosa para la comunidad. Por lo tanto, en algunos casos, los andinos deciden eliminar a esa persona. Entre los q'ero hay dos formas de luchar contra un depredador: debes domesticarlo o deshacerte de él; de lo contrario, se alimentará de ti y de la comunidad.

\section{Aquellos que han venido de afuera}

El pishtaco, ${ }^{5}$ llamado vampiro andino, es un ser que manifiesta el esquema de alteridad y depredación externa, dado que personifica a los extraños - blancos o mestizos. Los q'ero cuentan que los pishtacos matan a los indígenas, degollando o cortando la cabeza para chupar su grasa (wira) o sangre (yawar). Atacan con cuchillos o jeringas por la noche o en lugares deshabitados y alejados. Las sustancias robadas se utilizan para la producción de medicamentos, velas, jabón, campanas, combustible, electricidad o la construcción de puentes e iglesias (Blaisdell, Vindal 2014: 11). Los q'ero afirman también que la grasa humana se utiliza con fines rituales o para brujería.

Entre los q'ero, el miedo a los pishtacos sigue presente, principalmente entre las generaciones más antiguas, que tienen relativamente poca interacción con el mundo exterior. Durante mi investigación etnográfica, pude descubrirlo personalmente. Algunas personas mayores no querían hablar conmigo y cuando trataba de entablar contacto con ellas se escapaban o no reaccionaban. Como ejemplo puede servir Juana -una adorable anciana de 70 años- que no reaccionaba a mis preguntas, evitaba contacto visual o a veces sólo lanzaba respuestas lacónicas: "no sé nada"; "habla con otra persona"; "tengo que irme”. Después de un tiempo, el hijo de Juana me explicó que la razón de ese extraño comportamiento era el miedo al pishtaco. Mayormente, quienes son sospechosos de ser vampiros andinos, son los

\footnotetext{
${ }^{5} \mathrm{El}$ término pishtaco proviene de la palabra quechua pishtay y significa 'escalpar' o 'cortarse la cabeza'. Estas imágenes se encuentran en Perú (quechua) y Bolivia (aymara). Dependiendo de la región, también pueden encontrarse otros nombres como: kharisiri, lik'ichiri, ñakaq, sacaojos o degollador.
} 
foráneos: médicos, exploradores, turistas, alpinistas, antropólogos, aquellos que aparecen en las tierras de los q'ero. En el pueblo de Marcachea registré un relato sobre un hombre que fue visto varias veces entre marzo y abril de 2016 en las cercanías del pueblo: - "Tenía un sombrero y ropa de la ciudad. Pasaba por nuestras tierras con un machete, tenía 5 caballos. Dormía en las cuevas. Cazaba a los indios, y luego en caballos transportaba la grasa humana a Cusco". - Francisco de Qollpacucho (Hatun Q'ero) comentó que había cometido un error al enviar a su esposa enferma al hospital donde ésta murió. Afirmó que: "los indios mueren en los hospitales, los matan" y su grasa se utiliza para fines desconocidos. Vale la pena mencionar que entre los hombres jóvenes que a menudo viajan a ciudades y pueblos cercanos en cuestiones comerciales y relacionadas con el empleo remunerado, el miedo al pishtaco disminuye.

Algunos investigadores consideran que la representación del pishtaco se remonta a la época precolombina (Morote 1952; Ansión, Sifuentes 1989). En los tiempos incaicos eran especialistas que suministraban grasa, sangre y carne de origen humano y animal a los templos, que se utilizaban con fines rituales. El pishtaco era entonces el ayudante de sacerdotes que se ocupaba de los asesinatos rituales y seccionamiento del cuerpo de la víctima. Los sacrificios humanos y degollaciones como ritos religiosos son prácticas muy antiguas, lo que lleva a la conclusión de que la figura del degollador puede tener raíces en tiempos precoloniales (Ossio 1973; Ansión 1989; Millones 1990; de Pribyl 2010). Otros investigadores especulan que este concepto surgió en el siglo XVI como resultado de la violencia colonial (Ansión, Szemiński 1982: 212; Bastien 1985; Ansión, Sifuentes 1989: 69-70). En el siglo XX, los pishtacos fueron identificados con los blancos que trabajaban para las ONGs y con los representantes de las autoridades estatales. Estos conceptos fueron analizados también en el contexto de la violencia durante la guerra civil que tuvo lugar en el Perú en los años 80 y de las acciones terroríficas del Sendero Luminoso (Vergara Figueroa 2009). Actualmente. a quienes se acusa de "chupar grasa", son los mestizos: sacerdotes, policías, ingenieros, geólogos, médicos, soldados, así como los arqueólogos o antropólogos. Los estudios etnográficos recientes (p.ej. Rivière 1991; Crandon Malamud 1993; Fernández Juárez 2008) demuestran que el concepto del pishtaco - en el contexto de la situación histórica y sociopolítica - constituye una expresión de miedo a la modernidad y antipatía hacia los blancos, la visión del "indio" (Canessa 2000), la representación del Otro, la experiencia de la alteridad y la enfermedad como resultado de la somatización del miedo y manifestación de problemas emocionales y sociales (Theidon 2004). Esto muestra que los investigadores tratan el concepto de pishtaco en términos simbólicos o lo localizan en el contexto de trastornos psicosomáticos.

La investigación dirigida a la ontología y los términos indígenas nos permite ampliar la imagen y enriquecer las interpretaciones anteriores. Partiendo de los conceptos q'ero, demuestro que la alteridad es un tipo de depredación externa. Para analizar el concepto de pishtaco, en esta parte me refiero brevemente al concepto de enfermedad y cuerpo (individual y colectivo). Como mencionamos, el bienestar de los q'ero está estrechamente relacionado con el ayni (reciprocidad) 
y con el equilibrio de todos los elementos del cuerpo del individuo. La ruptura de estas reglas conduce a la enfermedad o muerte. Hay que señalar aquí que los contactos con extraños que no se comportan de acuerdo con allin kawsay (ethos cultural) pueden conducir a la enfermedad. Como señalan los q'ero, la transición a un modelo de comportamiento no q'ero (interiorización de la Otredad) significa el estado de deshumanización. Resulta significativo, que los ataques de pishtacos están relacionados con la movilidad a lugares desconocidos o habitados por poblaciones no andinas, p.ej. en las ciudades. Los ataques de pishtacos también pueden ocurrir en montañas en lugares alejados, p. ej. pastoreando animales fuera de las tierras de la comunidad. Los lugares indómitos -aquellos con los que el hombre no ha establecido ninguna relación de intercambio - pueden ser habitados por seres depredadores, no-humanos. Cualquier cosa que no sea familiarizada a través de ayni significa potencial peligro para integridad de la persona y su universo.

En esta parte tratamos de responder la pregunta: ¿por qué el pishtaco, como la personificación de alteridad, se alimenta de la grasa humana? La grasa (wira) uno de los sustratos corporales - representa un potencial económico, dado que proporciona fuerza física ( $k a l l p a)$ que permite el sustento de la familia, comunidad y pacha. También existe una estrecha relación entre la grasa y salud. Vale la pena señalar que, por regla general, los pishtacos atacan a los adultos - como los eslabones más fuertes en la cadena de producción y reproducción - dado que tienen más grasa que los niños (personas incompletas) y los ancianos (enfermos, débiles). Por añadidura, los q'ero creen que debido a su dieta natural la grasa de los andinos es mejor que los mestizos. El trabajo físico, que demuestra el bienestar, es un valor de mucha importancia, razón por la cual la pérdida de grasa, enfermedad o ruptura del ciclo de producción y lazos de ayni son signos altamente peligrosos. Además, la grasa tiene una función ritual importante. La grasa animal (de llama o alpaca) forma un elemento de la ofrenda para los apus y pachamamas, constituye el alimento más valioso para no-humanos. La falta de grasa en las ofrendas debilita sus poderes (Kato 2015). Como ya hemos mencionado bienestar de una pacha (micro-mundo, comunidad), formado por los hombres y otros no-humanos, está asociada con el intercambio de las sustancias (alimentación mutua). La interrupción de la red de intercambio conduce a la enfermedad tanto del individuo (enfermedad), familia o aldea (infértiles, desgracias, etc.) y de la pacha misma (sequías, plagas, etc.). Esto significa que, entre el cuerpo del individuo y su entorno (pacha), hay una analogía que se revela no sólo en el contexto de la estructura, sino también en el contexto de los procesos internos. Pacha, compuesta por los humanos y no- humanos, es una estructura cerrada e interconectada.

Dirijamos nuestra atención al hecho de que todas las representaciones de pishtacos están relacionadas con el acto de extraer sustancias del cuerpo individual o colectivo. El terrateniente se estaba beneficiando del trabajo de los andinos, que eran la mano de obra gratuita o barata, que nunca ha sido devuelta (ruptura de ayni). Como otro ejemplo puede servir la relación entre los nativos y la biomedicina. En los q'ero, he oído y he presenciado el miedo a los médicos y el hospital, dado que los q'ero creen que la extracción de sangre es un acto directo de robar 
el alma, que se encuentra en la sangre. Otro ejemplo constituye los investigadores, geólogos e ingenieros que están asociados con la minería. Para los q'eros la extracción de minerales - la sangre y la grasa de la tierra que corren en sus venas - es sinónimo de derrota del valor reproductivo y poder vital de la pacha lo que significa, en consecuencia, la debilitación de la comunidad, dado que la tierra enferma o debilitada no puede alimentar (dar cultivos) a las personas que viven alrededor. Por este motivo, el Otro (ingeniero, geólogo, etc.) es un representante de la relación depredadora que debilita la tierra, sin dejar nada a cambio, rompiendo la regla de ayni y la cadena de la circulación de las sustancias vitales en un micro-mundo (la aldea). Este acto material y literal de explotación (saqueo) se asocia con la acción contra el principio de ayni y conduce a la perturbación del bienestar local.

Desde la perspectiva q'ero, hay una relación entre la violencia y explotación de la tierra y enfermedad del individuo. Traté de demostrar que la clave para entender el fenómeno de pishtaco es el concepto de cuerpo (individual y colectivo). El acto de "chupar" la grasa tiene una dimensión literal - a través de la explotación de la tierra el potencial procreativo de la pacha se debilita y, en consecuencia, se debilita también el potencial vital de las personas que la habitan. El concepto de pishtaco representa un depredador externo que perturba el bienestar de las personas, de manera directa (depredación individual), como en el caso de un médico, sacerdote, antropólogo o hacendado, o indirecta (depredación colectiva), como en el caso de un geólogo o un ingeniero que explotan los recursos de la tierra.

\section{Conclusiones}

El presente artículo muestra tres modelos de depredación en la ontología q'ero. El primer modelo, representado por el esquema de olvido, es causado por la ruptura de los lazos de intercambio entre los humanos y no-humanos (apus, pachamamas, sirenas). La depredación de los no-humanos significa allí un mecanismo sustitutivo y esta forzada por el propio sistema basado en el flujo de las sustancias. Este modelo representa la depredación en una estructura cerrada, dado que los depredadores pertenecen al territorio definido por las fronteras de una pacha (micro-mundo). El sistema social establecido de tal manera, del que también forman parte los no-humanos, se basa en que todos los elementos del mundo participan en el intercambio continuo de bienes y sustancias, lo que permite que tanto los individuos como todo el sistema en su conjunto permanezcan. La interrupción del ciclo de intercambio obliga a los seres a suministrarse sustancias vitales a través de los actos de agresión. El segundo modelo representa también la depredación interna, pero se limita a la agresión de los mismos humanos quienes, como resultado del rechazo de ayni y de la deshumanización, se convierten en los kukuchis - condenados. Este ejemplo ilustra de una manera contundente que el concepto de la persona (runa) no es un estado estable y dado de una vez por todas. En la ontología q'ero, ser runa (humano) significa comportarse de acuerdo 
con las reglas de allin kawsay, el incumplimiento de las mismas puede conducir a enfermedades, la expulsión de la comunidad e incluso la muerte. A su vez, en el tercer caso de depredación que observamos en la cordillera de Vilcanota - representado por el esquema de alteridad- es la figura del pishtaco que lo personifica. El Otro - que no se comporta como un runa y no sigue las reglas de intercambioes el encargado de la depredación que se revela en la forma de extracción de las sustancias vitales del cuerpo individual (sangre, grasa) o colectivo (minerales). Esto conduce a la debilidad o enfermedad de la pacha y de todos los seres que la habitan.

Nuestro análisis nos lleva a la conclusión de que en la ontología q'ero se pueden identificar tres tipos de depredación:

1) interna (dentro de la misma pacha) entre diferentes colectivos de seres (humanos y no- humanos),

2) interna (dentro de la misma pacha) entre el mismo colectivo de seres (humanos),

3) externa (relacionada con otra pacha) que representa un agresor que viene de afuera (no-humanos).

El mundo andino está compuesto por micro-mundos (pachas) autosuficientes basados en la circulación de sustancias (relación de intercambio). En cada sistema ontológico existen las rupturas que en caso de los q'ero toman forma de la depredación interna y externa. Estos modelos depredadores para algunos (humanos) pueden significar la destrucción, pero la supervivencia para los otros (no-humanos). En este contexto la depredación significa un contrapeso y una especie de salida de evacuación -porque si por alguna razón el sistema basado en ayni no funciona - entonces cambia y se convierte para ser sostenible.

\section{Referencias citadas}

Alderman, J. (2015). Mountains as actors in the Bolivian Andes: The interrelationship between politics and ritual in the Kallawaya ayllus. The Unfamiliar, 5(1\&2), 33-45.

Allen, C. (1997) When Pebbles Move Mountains: inconicity and symbolism in Quechua ritual. En: R. Howard-Malverde (ed.), Creating Context in Andean Cultures. Oxford: Oxford University Press, 73-84.

Allen, C. (2002). La coca sabe: coca e identidad cultural en una comunidad andina. Cusco: Centro Bartolome de las Casas.

Allen, C. (2016). The Living Ones: Miniatures and Animation in the Andes. Journal of Anthropological Research, 72(4), 416-441.

Ansión, J. (1989). Pishtacos de verdugos a sacaojos. Lima: Tarea.

Ansión, J., Sifuentes, E. (1989). La imagen popular de la violencia a través de los relatos de degolladores. In: J. Ansión (ed.), Pishtacos: de verdugos a sacaojos. Lima: Tare, 61-108.

Ansión, J., Szemiński, J. (1982). Dioses y hombres de Huamanga. Allpanchis phurinqa, 19, 187-233.

Århem, K. (1990). Ecosofia Makuna. En: F. Correa (ed.), La selva humanizada (pp. 150-172). Bogotá: ICA. 
Bacigalupo, M. (1995). Métodos de curación tradicional mapuche. La práctica de la machi contemporánea en Chile. Enfoques en Atención Primaria, 9(4), 7-13.

Bastien, J. (1985). Mountain of the Condor: Metaphor and Ritual in an Andean Ayllu. Waveland: Prospect Heights L.

Bertelsen, B.E., Bendixsen, S. (2016). Recalibrating Alterity, Difference, Ontology: Anthropological Engagements with Human and Non-Human Worlds. En: B.E. Bertelsen, S. Bendixsen (eds.), Critical anthropological engagements in human alterity and difference. New York: Palgrave Macmillan, 1-41.

Blaisdell, A., Vindal Ødegaard, C. (2014). Losing fat, gaining treatments: the use of biomedicine as a cure for folk illnesses. The Andes Journal of Ethnobiology and Ethnomedicine, $10,52$.

Bolin, I. (1998). Rituals of respect: The secret of survival in the high Peruvian Andes. Austin: University of Texas Press.

Canessa, A. (2000). Fear and loathing on the kharisiri trail: Alterity and identity in the Andes. Journal of the Royal Anthropological Institute, 4:6, 705-720.

Carrithers, M., Candea, M., Sykes, K., Holbraad, M., Venkatesan, S. (2010). Ontology is Just Another Word for Culture: Motion Tabled at the 2008 Meeting of the Group for Debates in Anthropological Theory, University of Manchester. Critique of Anthropology, 30(2), 152-200.

Condori, B., Gow, R. (1982). Kay Pacha. Cuzco: CBC.

Crandon-Malamud, L. (1993). From the Fat of Our Souls: Social Change, Political Process and Medical Pluralism in Bolivia. Berkeley, Los Angeles: University of California Press.

De la Cadena, M. (2015). Earth Beings: Ecologies of Practice Across Andean Worlds. Durham: Duke University Press.

Descola, P. (1992). Society of nature and the nature of society. In: A. Kuper (ed.), Conceptualizing society (pp. 107-126). London, New York: Routledge.

Descola, P. (1996). Constructing natures: Symbolic ecology and social practice. In: P. Descola, G. Pálsson, Nature and society: Anthropological perspectives (pp. 82-102). London: Routledge.

Descola, P. (2013) Beyond nature and culture. Chicago: University of Chicago Press.

Fausto, C. (2007). Feasting on People: Eating Animals and Humans in Amazonia. Current Anthropology, 48(4), 497-530.

Fernández Juárez, G. (2008). Kharisiris en acción: cuerpo, persona y modelos médicos en el Altiplano de Bolivia. La Paz: Cuadernos de Investigación y Promoción de Campesino.

Fourtané, N. (2015). El condenado andino. Estudios de cuentos peruanos. Lima, Cusco: IFEA, CBC.

Gose, P. (1986). Sacrifice and the commodity form in the Andes. Man, 21, 296-310.

Greenway, Ch. (1998). Hungry earth and vengeful stars: Soul loss and identity in Peruvian Andes. Soc. Sci. Med., 48/8, 993-1004.

Gutiérrez, M. (2012). Ununchis. Cusco: Asociación Pukllasunchis.

Hallowell, A.I. (1967). Ojibwa Ontology, Behaviour and World View. En: S. Diamond (ed.), Culture in History: Essays in Honour of Paul Radin. New York: Columbia University Press.

Henare, A., Holbraad, M., Wastel, S. (eds.). (2006). Thinking through things: theorizing artefacts ethnographically. London, New York: Routledge.

Holbraad, M. (2012). Truth in Motion: The recursive Anthropology of Cuban Divination. Chicago: University of Chicago Press.

Holbraad, M., Pedersen, M. (2017). The Ontological Turn. Cambridge: Cambridge University Press.

Harvey, G. (2005). Animism: Respecting the Living World. London: Hurst \& Co. 
Isbell, B.J. (1974. Parentesco andino y reciprocidad. Kukaq: los que nos aman. En: Reciprocidad e intercambio en los Andes peruanos (pp. 110-152). Lima: Instituto de Estudios Peruanos.

Kato, T. (2015). Representación simbolica de lo marginado en el mundo andino. Tesis doctoral. Univerisdad Iberoamericana. Online: http://www.bib.uia.mx/tesis/pdf/014541/014541. pdf (ultimo acesso: junio 2020).

Knipper, M. (2006). El reto de la "medicina intercultural" y la historia de la "medicina tradicional" indígena contemporánea. In: Salud e interculturalidad en América Latina. Antropología de la salud y la crítica intercultural (pp. 413-432). Quito: Abya Yala.

López García, J. (2001). Comida y bases de la identidad aymara en el altiplano de Bolivia. En: Alimentación y sociedad en Iberoamérica y España. Cinco etnografías de la comida y la cocina (pp. 97-120). Cáceres: Universidad de Extremadura - Caja Duero.

Mayer, E. (1974), Reciprocidad e Intercambio en los Andes Peruanos. Lima: Instituto de Estudios Peruanos.

Martínez, G. (1983). Los dioses de los cerros en los Andes. Journal de la société des américanistes, 69, 85-115.

Millones, L. (1990). El retorno de las huacas. Estudios y documentos sobre el Taki Onkoy, siglo XVI. Lima: Instituto de Estudios Peruanos y Sociedad Peruana de Psicoanálisis.

Morote Best, E. (1952). El degollador (ñakaq). Tradición: Revista Peruana de cultura, 2.4, 67-91.

Núñez del Prado Castro, O. (2005). El hombre y la familia: Su matrimonio y organización político-social en Q'ero. Allpanchis, 1(1), 5-27.

Ossio, J. (ed.) (1973). Ideología mesiánica del mundo andino. Lima: Ed. Ignacio Prado Pastor.

Pazzarelli, F., Lema, V.S. (2018). Las formas de la historia. Equívocos, relaciones y memoria en los cerros jujeños. RAU Revista de Antropología de la UFSCAR, 10(2), 105-125.

De Pribyl, R. (2010). Evidencias médico antropológicas sobre el origen del Pishtaco. Revista Peruana de Medicina Experimental y Salud Publica, 27(1), 123-137.

Przytomska, A. (2017). "Hay que alimentar a la Madre Tierra". Haywakuy: un ritual de sanación e intercambio en la ontología de los q'ero. In: V. Torre, V. Anguiano (eds.), Recuperando la vida: Etnografías de sanación en Perú y México (pp. 113-138). Lima: Ríos Profundos editores.

Przytomska-La Civita, A. (2019). Apus: Non-human persons in the ontology of the Q'eros from the Cordillera Vilcanota (Peru). Etnografia. Praktyki, Teorie, Doświadczenia, 5, 35-63.

Przytomska-La Civita, A. (2020). El concepto del cuerpo y la persona entre los q'eros de la Cordillera Vilcanota, Perú. Estudios Latinoamericanos, 40 (en curso).

Ricard Lanata, X. (2007). Ladrones de sombra. El universo religioso de los pastores del Ausangate (Andes surperuanos). Lima: IFEA y CBC.

Rivera Andía, J.J. (2019). Non-humans in Amerindian South America: Ethnographies of Indigenous Cosmologies, Rituals and Songs. New York: Berghahn Books.

Rivière, G. (1991). Likichiri y Kharisiri. A propósito de las representaciones del 'otro' en la sociedad aymara. Bulletin de l'Institut Français d'Études Andines, 20(1), 23-40.

Salas Carreño, G. (2019). Lugares parientes. Comida, cohabitación y mundos andinos. Lima: PUCP.

Salomon, F. (1991). Introduction. In: The Huarochirí manuscript. Edited and translated by Frank Salomon and George Urioste (pp. 1-38). Austin: University of Texas Press.

Sax, M. (2011). An ethnography of feeding, perception and place in the Peruvian Andes (where hungry spirits bring illness and wellbeing). New York: Edwin Mellen Press.

Taussing, M. (1980). The Devil and Commodity Fetishism in South America. University of North Carolina Press. 
Theidon, K. (2004). Entre Prójimos: El conflicto armado interno y la politica de la reconciliación en el Perú. Lima: Instituto de Estudios Peruanos.

Tola, F. (2012). Yo no estoy solo en mi cuerpo. Cuerpos-personas múltiples entre los qom (tobas) del Gran Chaco. Buenos Aires: Biblos/Culturalia.

Tola, F. (2016). El "giro ontológico" y la relación naturaleza/cultura. Reflexiones desde el Gran Chaco. Apuntes de Investigación del CECYP, 27, 128-139.

Tomoeda, H. (2005). Sirenas andinas. In: H. Tomoeda, L. Millones, Pasiones y desencuentros en la cultura andina). Lima: Fondo Editorial del Congreso del Perú.

Vergara Figueroa, A. (2009). Nakaq: una historia del miedo. Del mito al rumor y del rumor al mito, 23, 131-156.

Vilaça, A. (1992). Comendo como gente. Formas do canibalismo wari. Rio de Janeiro: ANPOCS/ Editora da UFRJ.

Viveiros de Castro, E. (1998). Cosmological Deixis and Amerindian Perspectivism. Journal of the Royal Anthropological Institute, 4, 469-488.

\section{SUMMARY}

The relation of predation between humans and non-humans in the ontology of the Q'eros from the Vilcanota mountain range, Peru

The anatomy of human and non-human (apus, pachamamas, the dead etc.) relations and dependencies manifests itself in different types of daily practices and rituals (agriculture and herding, mobility, alimentation, ritual songs, shamanic and medicinal practices) and reveals ontological schemes of exchange and predation. Interestingly, both schemes can be expressed through the idiomatic expression of "feeding". This implies that the purpose of relationships between personal beings is to feed each other through reciprocal practices (exchange) or feed on others (predation). In this paper, we analyze the scheme of predation among the Q'eros, which takes the forms of seduction, sexual intercourse, cannibalism and kidnapping. Different types of predation were grouped into three modalities (oblivion, breaking the taboo and otherness) that constitute the axis of the narrative and, at the same time, represent the origins or causes of these relations.

Keywords: predation, ontology, Q'eros, Quechua, Andes, non-humans 